\title{
DÜBLIN
}

Technological University Dublin

ARROW@TU Dublin

Articles

School of Electrical and Electronic Engineering

2016-10

\section{Pattern Reconfigurable Back-to-Back Microstrip Patch Antenna}

\author{
Kansheng Yang \\ Technological University Dublin \\ Xiulong Bao \\ Technological University Dublin, xiulong.bao@tudublin.ie \\ Patrick McEvoy \\ Technological University Dublin, patrick.mcevoy@tudublin.ie
}

See next page for additional authors

Follow this and additional works at: https://arrow.tudublin.ie/engscheleart2

Part of the Electrical and Electronics Commons, Electromagnetics and Photonics Commons, and the Electronic Devices and Semiconductor Manufacturing Commons

\section{Recommended Citation}

Yang, K., Bao, X., McEvoy, P. \& Ammann, M. (2016). Pattern reconfigurable back-to-back microstrip patch antennalET Microwaves, Antennas \& Propagation, vol.10(13) pp.1390-1394. doi:10.1049/iet-

map.2015.0814

This Article is brought to you for free and open access by the School of Electrical and Electronic Engineering at ARROW@TU Dublin. It has been accepted for inclusion in Articles by an authorized administrator of ARROW@TU Dublin. For more information, please contact arrow.admin@tudublin.ie, aisling.coyne@tudublin.ie, gerard.connolly@tudublin.ie.

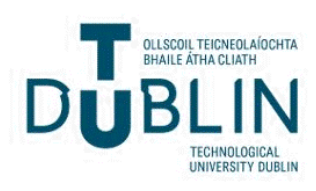


Authors

Kansheng Yang, Xiulong Bao, Patrick McEvoy, and Max Ammann

This article is available at ARROW@TU Dublin: https://arrow.tudublin.ie/engscheleart2/195 


\title{
A Dual-Stub Ka-Band Vivaldi Antenna with Integrated Bandpass Filter
}

\author{
Kansheng Yang ${ }^{1,2^{*}}$, Manh-Ha Hoang ${ }^{1,2}$, Xiulong Bao ${ }^{1}$, Patrick McEvoy ${ }^{1,3}$, Max J. Ammann ${ }^{1,2,3}$ \\ ${ }^{1}$ Antenna \& High-Frequency Research Centre, Dublin Institute of Technology, Ireland \\ ${ }^{2}$ CONNECT - Ireland's research centre for Future Networks and Communications \\ ${ }^{3}$ School of Electrical \& Electronic Engineering, Dublin Institute of Technology, Ireland \\ *kansheng.yang@mydit.ie
}

\begin{abstract}
A dual-stub coplanar Vivaldi antenna with a parasitic element is presented. The dual-stub is coupled between the parasitic element and two tapered slots. The parasitic element shape and size is optimised. The use of slits on the outer edge of the ground plane is shown to provide control of beamwidth and maximum gain. A bandpass filter is used for performance control and sub-harmonic suppression.
\end{abstract}

\section{Introduction}

The Vivaldi antenna was first proposed by Gibson in 1979 [1]. The travelling wave antenna couples energy along the inner edge of the flared slot and produces endfire radiation. This is widely used for beam scanning in radio astronomy [2] and phased arrays [3].

Recent Vivaldi antenna research has focused on performance improvement in both gain and directivity [4][8]. An elliptical parasitic element was added to an Antipodal Vivaldi Antenna (AVA), which was reported to improve the directivity and gain in Ka-band [9]. A co-planer Vivaldi antenna using a double-slot structure fed by dual-stubs was also reported [10]. The inner flares are shorter for both slots thus two outer flares can enhance the E-field plane wave. This can improve the directivity in Ku-band. Similarly, a doubleantipodal structure is reported in [11], where higher gain is achieved using two inner tapered edges which are shorter in length compared to the outer tapered edges. A notable addition of slits on the outer edge is used to improve the radiation pattern and edge diffraction [11]-[15], the widths and gaps of the edge slits are optimised.

The control of gain over frequency for an ultrawideband (UWB) Vivaldi antenna is challenging. For example, the gain of one UWB Vivaldi antenna design [16] is reported to vary from $3 \mathrm{dBi}$ to $12 \mathrm{dBi}$ over the frequency band. A bandpass filter section can be used to reduce the matched bandwidth providing radiation performance control as well as improving the sub-harmonic suppression.

An early study of filter integration within a coplanar Vivaldi antenna is carried out in [17]. A narrow band Vivaldi antenna is designed with a bandpass filter for mm-wave applications. It shows that introducing a parasitic element in antenna design can improve the gain.

In this paper, detailed approaches to design a dual-stub coplanar Vivaldi antenna with a parasitic element at $28 \mathrm{GHz}$ is presented. The parasitic element is optimised in shape and size for higher gain. The slits on the edge of the ground plane are studied to improve the radiation performance. Differential dual-stub excitation is critical to the design and the mechanism is explained. Key parameters are studied to adjust the frequency response and radiation characteristics. The presented structure with filter is low-profile and simple to fabricate.

\section{Antenna Design}

\subsection{Antenna Configuration}

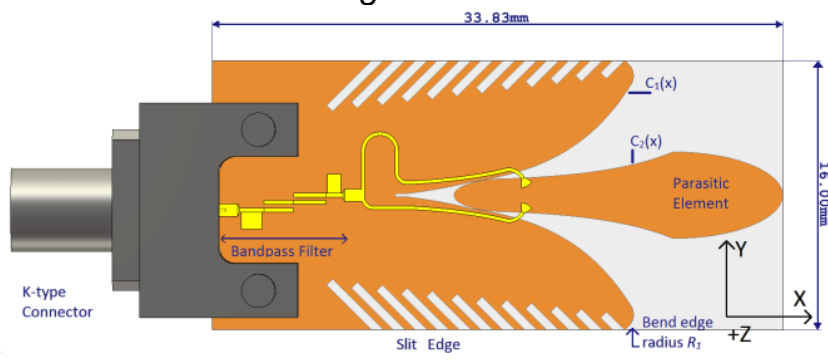

Fig. 1. Antenna geometry with outer dimensions

The coplanar Vivaldi antenna is prototyped on Rogers RT/duroid 5880 substrate $\left(\varepsilon_{r}=2.2\right.$ and $\left.\tan \delta=0.0009\right)$ with dimensions $33.8 \times 16 \times 0.25 \mathrm{~mm}^{3}\left(3.15 \times 1.49 \times 0.02 \lambda^{3}\right)$. The antenna geometry is shown in Fig. 1. A bandpass filter is implemented in the feed and terminated with a K-type $(2.92 \mathrm{~mm})$ connector. The bottom side of the board is symmetrical in the $\mathrm{x}$-axis and the exponential profile curve $C_{i}(x)$ used to design this is:

$$
C_{i}(x)= \pm a_{i} \times e^{p_{i} x}
$$

where $a_{l}=0.15$ and $p_{l}=0.25$. The minimum width of the inner tapered slot is $0.2 \mathrm{~mm}$. An edge bend radius of $R_{I}=1 \mathrm{~mm}$ was applied to the point where the taper meets the ground plane edge (see Fig. 1) to increase the gain by $0.44 \mathrm{~dB}$ The parasitic element is introduced into the throat of the exponential flared aperture and consists of two semi-elliptical

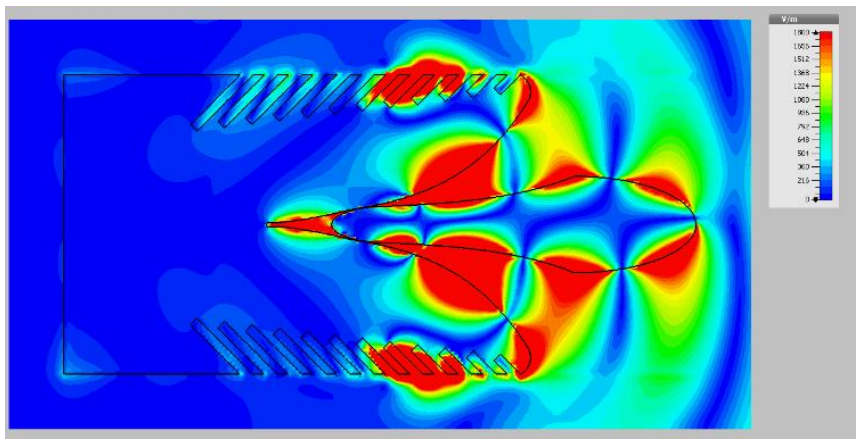

Fig. 2. Antenna E-field simulation 
shapes with an exponential curved shape in the middle. The dual-stub structure couples to the parasitic element which is optimized in shape to improve the gain and end-fire radiation characteristics (further discussed in Section. 3). On the top side of the board, the differential feeds follow the exponential curve connected to the two fan-shaped stubs of radius $0.7 \mathrm{~mm}$ and angle of $60^{\circ}$, which excite the tapered slot with the parasitic element. The E-field simulation, shown in Fig. 2, demonstrates this arrangement. It provides improved coupling to the tapered slots with similar amplitude and $180^{\circ}$ phase difference. This way, the E-field directions on both sides of the parasitic element are the same, therefore further enhancing the radiation performance. Notably, the calculated E-field distribution is slightly asymmetric, this is due to the feed configuration.

\subsection{The Bandpass Filter}

The filter section design is shown in Fig. 3. The twostage coupled filter is connected to two open shunt stubs for matching purposes. The dimensions shown in the figure are

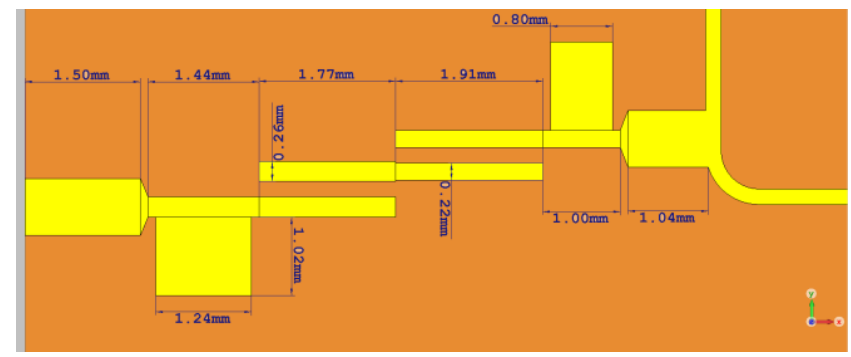

Fig. 3. Detailed bandpass filter layout

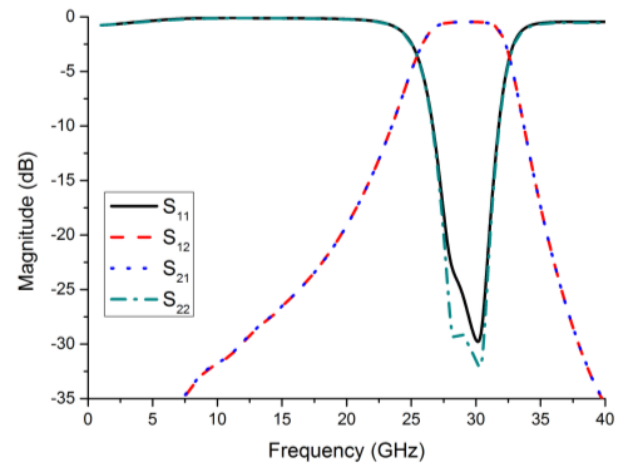

$a$

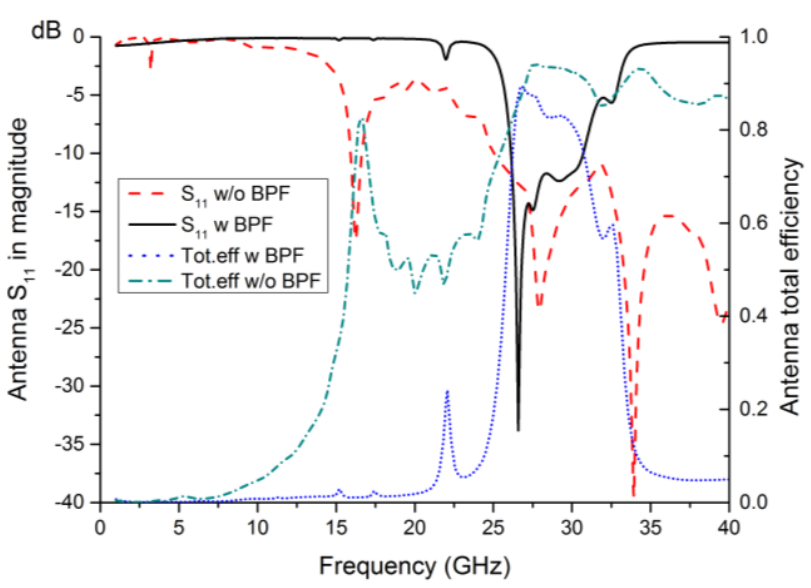

$b$

Fig. 4. Filter performance simulation

(a) Two port filter section simulation, (b) Antenna $S_{11}$ and total efficiency simulation with and without filter optimised for low insertion loss, good impedance matching and sufficient bandwidth. The simulated response of this twoport filter is shown in Fig. 4a. This low-loss bandpass filter is designed at the centre frequency of $28 \mathrm{GHz}$ with a $0.5 \mathrm{~dB}$ insertion loss and a 3-dB bandwidth from $25.48 \mathrm{GHz}$ to 32.54 GHz. The simulated S11 of the antenna with and without the filter is shown in Fig. 4b. It is noted that even the differential feeds are designed at $28 \mathrm{GHz}$, the Vivaldi antenna without filter provides a wide bandwidth starting from $25.8 \mathrm{GHz}$ to $43.9 \mathrm{GHz}$. However, the radiation pattern is tilted outside the frequency of interest due to the phase difference in the two stubs.

The filter improves the matching in the desired band and suppresses the sub-harmonics significantly. The total efficiency experiences a drop of 8.9 percentage points $(93.8 \%$ to $84.9 \%$ ) at $28 \mathrm{GHz}$ due to the filter.

\section{Antenna Performance Study}

\subsection{The Parasitic Element Geometry}

Similar to [9], the position of the parasitic element should be located close to the throat of the flare to improve the coupling. In the research, an elliptically shaped radiator was first designed as the parasitic element, it was then
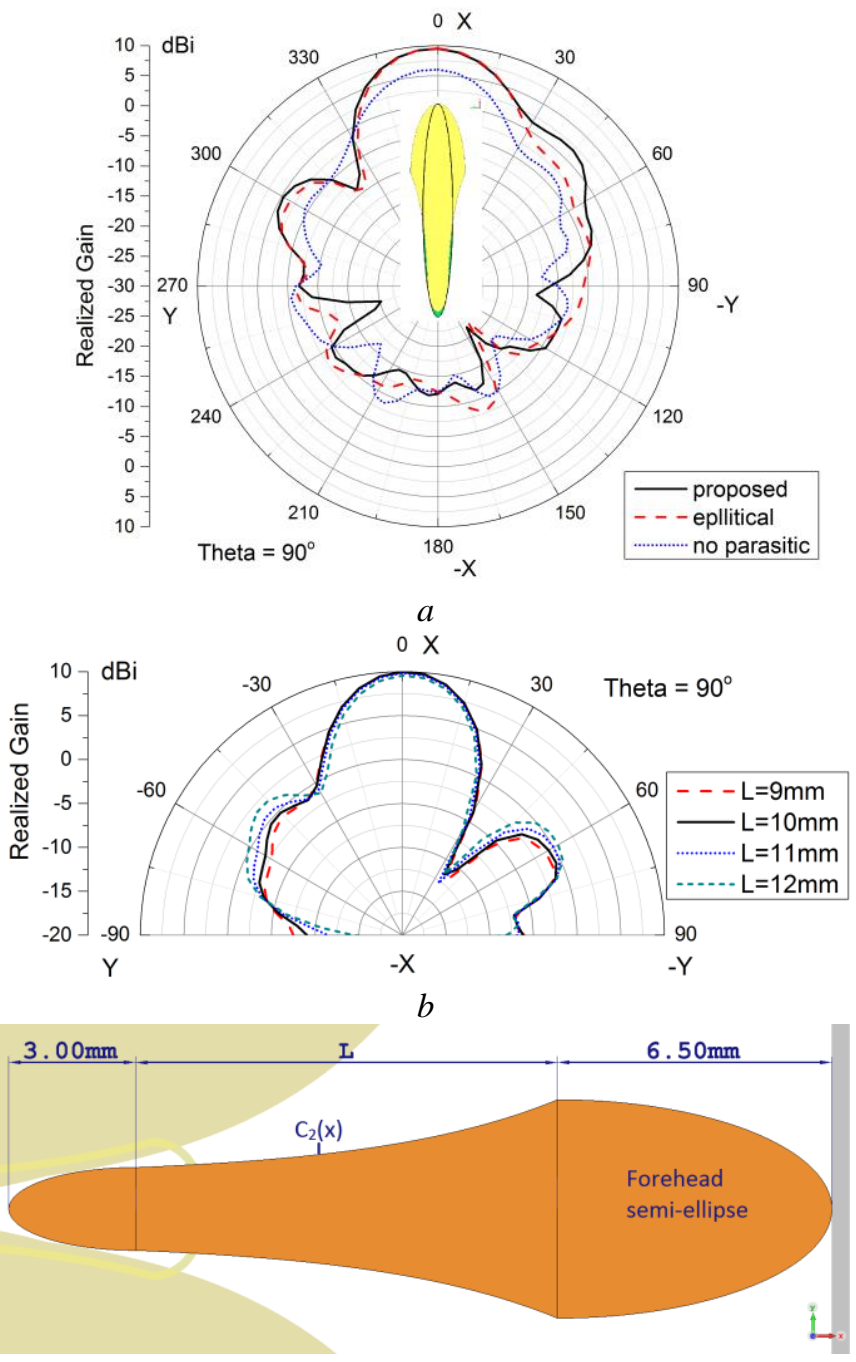

Fig. 5. Parasitic element study

(a) Parasitic shape comparison, (b) Parameter study on $L$,

(c) The geometry of the parasitic element 
replaced by the proposed shape with the same length shown in Fig. 5a. It can be observed, that the proposed shape has a higher gain compared to that of the elliptical shape. Therefore, the shape of the parasitic element can improve the radiation gain of the antenna. A further parametric study on the curve length $L$ is implemented while the total length of the parasitic element remains the same, the results are shown in Fig $5 \mathrm{~b}$. The exponential curve $C_{2}(x)$ uses the same function from Eq. (1) where $a_{2}=0.2$ and $p_{2}=0.23$, which is already optimised for the highest gain. As shown in Fig. 5c, the forehead semi-ellipse becomes wider as $L$ increases, resulting in higher side lobes and lower maximum gain. The highest realised gain and lowest side lobes can be observed in Fig. 5b when $L=10 \mathrm{~mm}$.

\subsection{Parametric Study on the Vivaldi Edge}

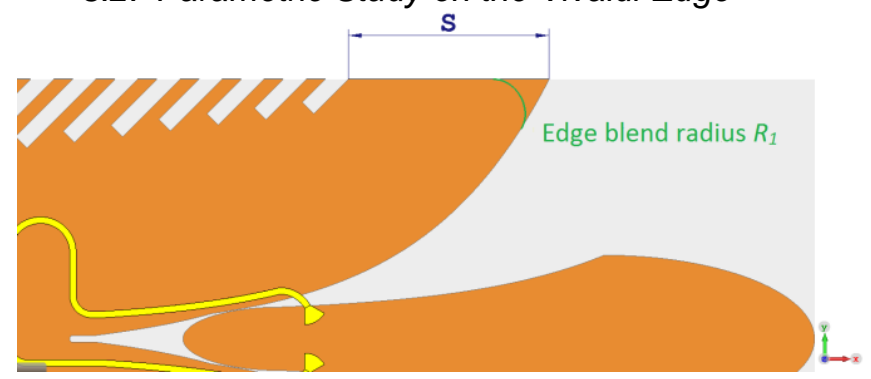

Fig. 6 Geometry zoom in on the slit edge

The slits are parallel slots cut into the outer ground plane edge of the Vivaldi, as shown in Fig. 6. In this design, they are placed at the tip of the Vivaldi shape, $45^{\circ}$ to the yaxis with the slit width of $0.5 \mathrm{~mm}$, the slit separation of $0.8 \mathrm{~mm}$ and a linear increment $0.25 \mathrm{~mm}$ in length starting from $1.5 \mathrm{~mm}$ (1st slit length).

From Fig. 7, it can be seen that the front-to-back ratio improved significantly by $11.9 \mathrm{~dB}$ with the introduction of slits to the structure. Adding 4 more slits (from 8 to 12 slits), the squinted radiation direction $5^{\circ}$ is modified back on boresight $\left(0^{\circ}\right)$ with the same radiation gain and half-power bandwidth. The side lobe is also reduced by $1 \mathrm{~dB}$. The comparison of the slits parallel to the y-axis and $45^{\circ}$ is presented in Fig. 7. The proposed method offers $1.4 \mathrm{~dB}$ greater maximum gain and lower side lobes.

The slit position from the tip $S$ is studied in Fig 8 and Table 1. As a balance between gain and beamwidth in the $\theta=90^{\circ}$ plane, the presented design can be adjusted for

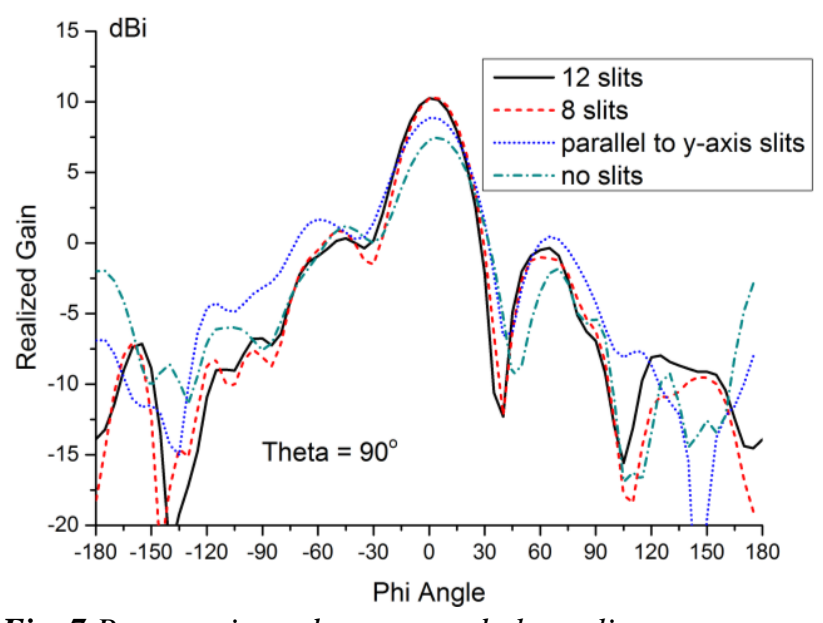

Fig. 7 Parametric study on ground plane slits

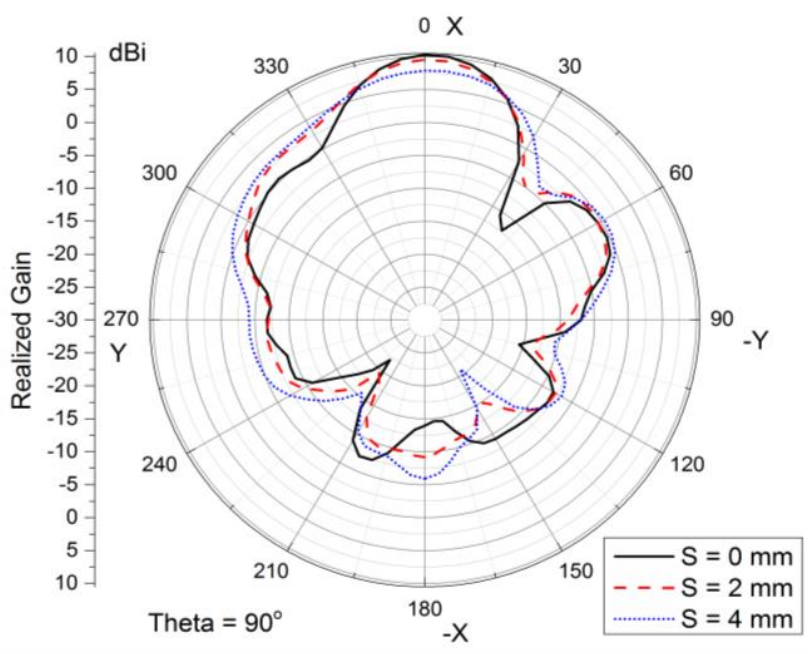

Fig. 8 Parametric study on slit position $S$

Table I Summary of gain and HPBW in Fig. 8

\begin{tabular}{lll}
$\mathrm{S}(\mathrm{mm})$ & $\begin{array}{l}\text { Maximum Gain } \\
(\mathrm{dBi}) \text { in } \theta=90^{\circ}\end{array}$ & $\begin{array}{r}\text { Hal } \\
\text { bea } \\
(\mathrm{H}\end{array}$ \\
\hline & & \\
2 & 10.24 & $30.3^{\circ}$ \\
4 & 9.52 & $34.2^{\circ}$ \\
\hline
\end{tabular}

pursuing more than $10 \mathrm{dBi}$ realised gain for $S=0 \mathrm{~mm}$ or wide HPBW for $S=4 \mathrm{~mm}$.

Combing the results from Fig. 2 and 7, the addition of ground plane slits provides additional filtering on the ground plane edge, which acts as a refelctor to the edge current. Hence, the the front-to-back ratio is increased, with improved end-fire radiation.

\subsection{Final Results Presentation}

Fig. 9 shows the simulated and measured $S_{11}$. The antenna radiates at $28 \mathrm{GHz}$ with a measured $10 \mathrm{~dB}$ impedance bandwidth of $25.99-31.49 \mathrm{GHz}(\Delta=4.96 \mathrm{GHz})$ and simulated $26.11-30.71 \mathrm{GHz} \quad(\Delta=4.6 \mathrm{GHz})$. The simulated total efficiency is $84.9 \%$. The measured and simulated radiation pattern is shown in Fig. 10. The maximum measured realised gain at $28 \mathrm{GHz}$ is $8.48 \mathrm{dBi}$. The measured $\mathrm{HPBW}$ is $35^{\circ}$ in the $\theta=90^{\circ}$ plane and the

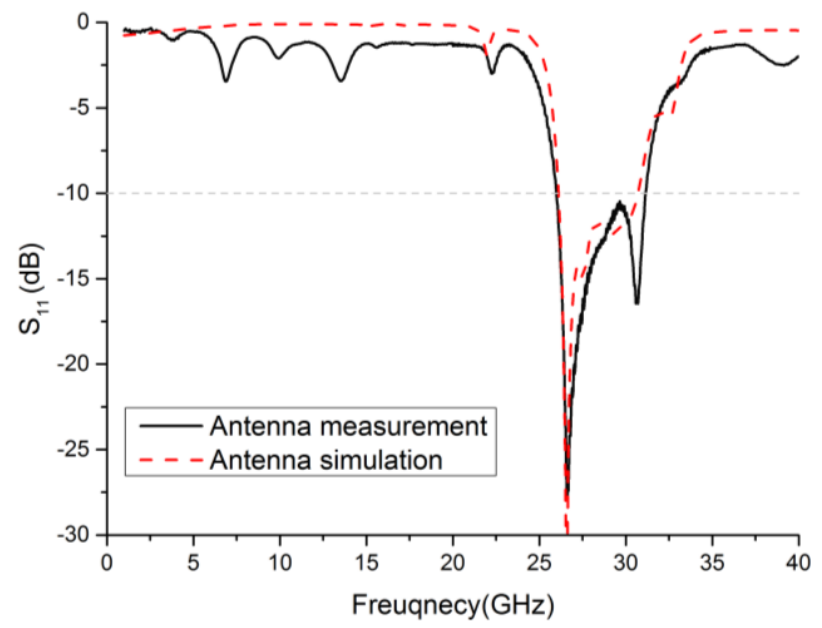

Fig. 9 Simulated and measured $S_{11}$ 
beamwidth for which the gain is greater than $0 \mathrm{dBi}$ is $82^{\circ}$. For the $\varphi=0^{\circ}$ plane, the measured HPBW is $75^{\circ}$ with a $110^{\circ}$ beamwidth for $0 \mathrm{dBi}$ gain. Good agreement between simulation and measurement was achieved. The simulated and measured realised gain over frequency at boresight is presented in Table 2. Fig. 11 shows the prototyped antenna.
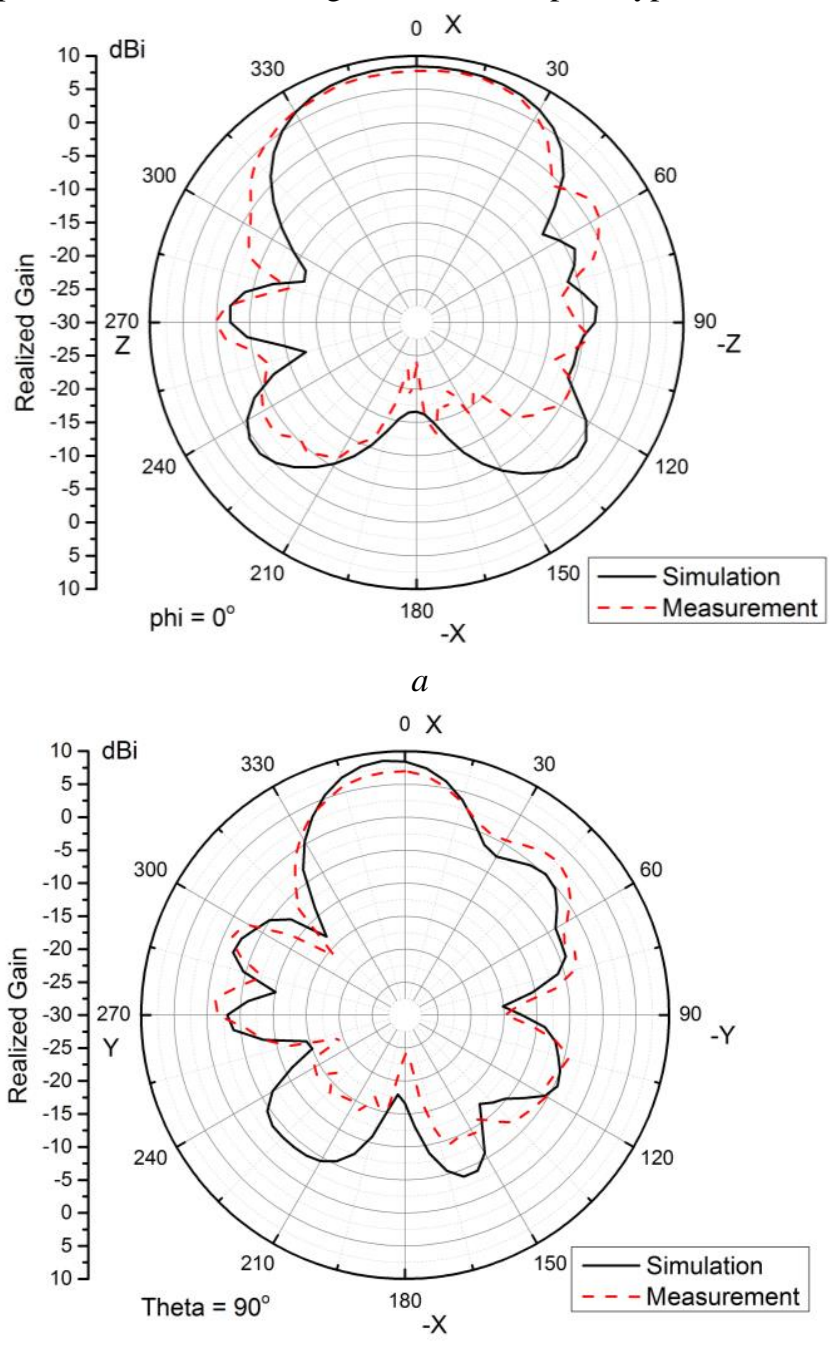

$b$

Fig. 10 Simulated and measured realised gain at $28 \mathrm{GHz}$ (a) $\varphi=0^{\circ}$ cut, (b) $\theta=90^{\circ}$ cut

Table 2 Measured and simulated gain over frequency

\begin{tabular}{lcc}
$\begin{array}{l}\text { Frequency } \\
(\mathrm{GHz})\end{array}$ & $\begin{array}{c}\text { Simulated Gain } \\
(\mathrm{dBi})\end{array}$ & $\begin{array}{c}\text { Measured Gain } \\
(\mathrm{dBi})\end{array}$ \\
\hline
\end{tabular}

\begin{tabular}{lll}
27 & 7.56 & 7.23 \\
28 & 9.4 & 8.51 \\
29 & 8.5 & 7.57 \\
30 & 7.59 & 7.23 \\
31 & 6.4 & 6.35 \\
\hline
\end{tabular}

\section{Conclusion}

A dual-stub fed Vivaldi antenna with a parasitic element in the throat flare is proposed. The reported antenna provides greater coupling to the tapered slots achieving a higher gain of $8.48 \mathrm{dBi}$. The parasitic element is optimised in shape for better radiation performance. The position of the edge slits is shown to provide control of end-fire radiation

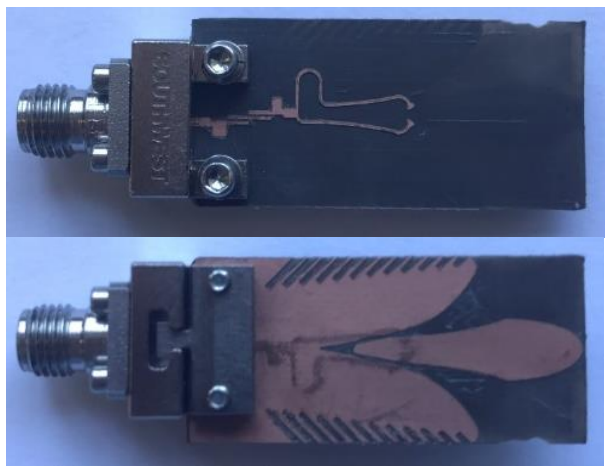

Fig. 11 Photo of prototype antenna

characteristics. The bandpass filter section is added at the source end for harmonic suppression. The suggested application for this coplanar Vivaldi antenna is emerging $5 \mathrm{G}$ base stations and fixed terminals at $28 \mathrm{GHz}$ for directional communication as well as imaging or sensing.

\section{Acknowledgments}

This publication has emanated from research conducted with the financial support of Science Foundation Ireland (SFI) and is co-funded under the European Regional Development Fund under Grant Number 13/RC/2077.

\section{References}

[1] P. J. Gibson, 'The Vivaldi Aerial', in Microwave Conference, 1979. 9th European, 1979, pp. 101-105.

[2] E. W. Reid, L. Ortiz-Balbuena, A. Ghadiri, et al., 'A 324Element Vivaldi Antenna Array for Radio Astronomy Instrumentation', IEEE Trans. Instrum. Meas., vol. 61, no. 1, pp. 241-250, Jan. 2012.

[3] J. Shin and D. H. Schaubert, 'A parameter study of stripline-fed Vivaldi notch-antenna arrays', IEEE Trans. Antennas Propag., vol. 47, no. 5, pp. 879-886, May 1999.

[4] M. Moosazadeh, S. Kharkovsky, J. T. Case, et al., 'Antipodal Vivaldi antenna with improved radiation characteristics for civil engineering applications', Antennas Propag. IET Microw., vol. 11, no. 6, pp. 796-803, 2016.

[5] M. Amiri, F. Tofigh, A. G. Yazdi, et al., 'Exponential Antipodal Vivaldi Antenna With Exponential Dielectric Lens', IEEE Antennas Wirel. Propag. Lett., vol. PP, no. 99, pp. 1-1, 2017.

[6] J. Puskely, J. Lacik, Z. Raida, et al., 'High-Gain Dielectric-Loaded Vivaldi Antenna for a -Band Applications', IEEE Antennas Wirel. Propag. Lett., vol. 15, pp. 2004-2007, 2016.

[7] M. Moosazadeh and S. Kharkovsky, 'A Compact HighGain and Front-to-Back Ratio Elliptically Tapered Antipodal Vivaldi Antenna With Trapezoid-Shaped Dielectric Lens', IEEE Antennas Wirel. Propag. Lett., vol. 15, pp. 552-555, 2016.

[8] B. Zhou and T. J. Cui, 'Directivity Enhancement to Vivaldi Antennas Using Compactly Anisotropic Zero-Index Metamaterials', IEEE Antennas Wirel. Propag. Lett., vol. 10, pp. 326-329, 2011.

[9] I. T. Nassar and T. M. Weller, 'A Novel Method for Improving Antipodal Vivaldi Antenna Performance', IEEE Trans. Antennas Propag., vol. 63, no. 7, pp. 3321-3324, Jul. 2015.

[10] Y. W. Wang, G. M. Wang, and B. F. Zong, 'Directivity Improvement of Vivaldi Antenna Using Double-Slot 
Structure', IEEE Antennas Wirel. Propag. Lett., vol. 12, pp. 1380-1383, 2013.

[11] Y. Zhang, E. Li, C. Wang, et al., 'Radiation Enhanced Vivaldi Antenna With Double-Antipodal Structure', IEEE Antennas Wirel. Propag. Lett., vol. 16, pp. 561-564, 2017.

[12] A. M. D. Oliveira, M. B. Perotoni, S. T. Kofuji, et al., 'A Palm Tree Antipodal Vivaldi Antenna With Exponential Slot Edge for Improved Radiation Pattern', IEEE Antennas Wirel. Propag. Lett., vol. 14, pp. 1334-1337, 2015.

[13] M. Moosazadeh, S. Kharkovsky, and J. T. Case, 'Microwave and millimetre wave antipodal Vivaldi antenna with trapezoid-shaped dielectric lens for imaging of construction materials', Antennas Propag. IET Microw., vol. 10, no. 3, pp. 301-309, 2016.

[14] M. Moosazadeh, S. Kharkovsky, J. T. Case, et al., 'Miniaturized UWB Antipodal Vivaldi Antenna and Its Application for Detection of Void Inside Concrete Specimens', IEEE Antennas Wirel. Propag. Lett., vol. 16, pp. 1317-1320, 2017.

[15] M. Shimizu, H. Shirai, and R. Sato, 'Multiple edge interaction effect to plane wave scattering by a wide and thick slit', in 2015 International Symposium on Antennas and Propagation (ISAP), 2015, pp. 1-3.

[16] J. Bai, S. Shi, and D. W. Prather, 'Modified Compact Antipodal Vivaldi Antenna for 4-50 GHz UWB Application', IEEE Trans. Microw. Theory Tech., vol. 59, no. 4, pp. 10511057, Apr. 2011.

[17] K. Yang, A. Loutridis, X. Bao, et al., 'A coplanar vivaldi antenna with integrated filter for Ka-band', in 2016 Loughborough Antennas Propagation Conference (LAPC), 2016, pp. 363-366. 